\title{
A Study on the Prevalence of Bovine Trypanosomiasis and its Associated Risk Factors in Tarcha Zuria District, Dawuro Zone Southern Ethiopia
}

\author{
Esayas Balcha Madalcho* \\ Wolaita Sodo Tsetse Fly and Trypanosomosis Control Station, Sodo, Ethiopia
}

*Corresponding Author: Esayas Balcha Madalcho, Wolaita Sodo Tsetse Fly and Trypanosomosis Control Station, Sodo, Ethiopia

\begin{abstract}
A cross-sectional study was conducted from February 12, 2018 to February 19, 2018 to determine the prevalence of bovine trypanosomosis and to identify risk factors associated with trypanosome infection in Tarcha zuria district of Dawuro zone, Southern Nation Nationalities and Peoples Regional States, Ethiopia. 117 cattle were randomly sampled from three purposively selected peasant associations in the study area. In the parasitological survey, blood samples from study animals were examined using a buffy coat technique; and the trypanosome species identified from positive animals was Trypanosome congolense. The packed cell volume (PCV) value of each animal was also measured using hematocrit reader. The overall prevalence of trypanosomosis in the study area was found to be $6.84 \%(95 \% \mathrm{CI}=3.00-13.03)$. The prevalence of Trypanosome infection was $9.1 \%, 5.48 \%$ in male and female; $7.14 \%, 12.5 \%, 4.44 \%$ in animals with poor, medium and good body conditions; 2.94\%, 11.11\%, 3.44\% in animals with age under 3 years, 3-6 years and above 7 years respectively. The prevalence of Trypanosome infection was $7.69 \%$ in both Wara and Sore, while a $5.13 \%$ was recorded in Aba Dahi peasant associations respectively. However, none of these risk factors showed statistical association with the prevalence of Trypanosome infection in cattle of the study area. The mean PCV value (\%) of parasitaemic and aparasitaemic animals during the study period were 20.34 and 26.38 with a statistically significant $(p<0.05)$ difference between the two groups. It was concluded that the present work evidenced that trypanosomosis has continued to pose a considerable threat to cattle production in the study area warranting an integrated control and prevention to safeguard cattle production and productivity.
\end{abstract}

Keywords: Cattle, Prevalence, Risk Factors, Tarcha Zuria District, Trypanosome

\section{INTRODUCTION}

Trypanosomosis is one of the diseases that are caused by flagellated protozoan parasites belong to the genus Trypanosoma. Trypanosomosis limits the extension of natural herds particularly in Africa where the presence of tsetse fly density access to fertile woody and savannah lands with good grazing potential and livestock rearing (Abebe and Jobre, 1996; Uilenberg, 1998). It is a serious constraint to agricultural production in extensive areas of the tsetse infested regions (Alsan, 2012; Slingenbergh, 1992) which accounts over 10 million square kilometers of the tropical Africa. According to Abebe (2005) the reduced capacity for work animals is also a very important factor where $80 \%$ of the traction power in African agriculture is provided by animals. Generally, there is a great threat of trypanosomosis which impedes the economic development of sub-Saharan Africa and reasonable for the incalculable toll of human health. The disease trypanosome is prevalent in Ethiopia including the study area. The reason for the considerable prevalence of the disease is basically agreed as the vast burden of the fly which is Tsetse fly by its various species. The good intervention to alleviate the disease from the country was considered as making the country free from the specific insect. However, controlling this insect gets challenged by many factors or challenges. For instance, the demographic and food security challenge, the challenge of sustainable agriculture, rural development and natural endowments, the challenge of drug control, the challenge of a coordinated approach, the challenge of selecting technologies and the sequence in which they are applied (Leta et al., 2015).

Tsetse flies are biological vectors of African trypanosomosis in animals and man. Their distribution and prevalence are most influenced by spatial factors such as climate, vegetation and land utilization 
(Rogers et al., 1996). The occurrence and impact of trypanosomosis, on the other hand, depends on tsetse challenge, host distribution, livestock breeds, farming practices and control practices. Tsetse challenge is determined by the product of relative tsetse density, trypanosome prevalence in tsetse and the proportion of meals obtained by the tsetse from a defined host (Leak, 1988).

There are 30 species or subspecies of the tsetse fly, of which 22 are recognized as of economic importance because of their role in the transmission of pathogenic trypanosomes. There is a fairly well defined limit to their spread, the northern and southern limits. Generally, distribution of the different species of tsetse is determined principally by climate and influenced by altitude, vegetation and the presence of suitable host animals. The distribution varies markedly some are widespread all over sub-Saharan Africa, while others have relatively limited distribution (ILEMOBADE, 2009, Kuzoe and Schofield, 2004).

In Ethiopia, trypanosomosis is one of the most important disease limiting livestock productivity and agricultural development due to its high prevalence in the most arable and fertile land of South-West and North West part of the country following the greater river basins of Abay, Omo, Ghibe and Baro with a high potential for agricultural development. Currently, about 220,000 km2 areas is infested with tsetse flies, namely, Glossina pallidipes, Glossina morsitans, Glossina fuscipes, Glossina tachinoides and Glossina longipennis. The most important trypanosome species affecting livestock in Ethiopia are Trypanosoma congolense, Trypanosoma vivax and Trypanosoma brucei, in cattle, sheep and goat. Trypanosoma evansi in camel and Trypanosoma equiperdum in horse (Abebe, 2005). Trypanosomosis is found to be one of top health problems of livestock in most lowlands of western and southwestern Ethiopia. However, the distribution and the magnitude of the disease and its vectors are not well understood. Therefore, the aim of this research was to estimate the prevalence of trypanosomosis in cattle and associated risk factors in Tarcha Zuria District Dawuro Zone, Southern Ethiopia.

Therefore, the study was commenced with the following objectives:

\section{Genera objectives:}

To define the prevalence of bovine trypanosomosis and associated risk factors

\section{Specific Objective:}

To determine the prevalence of trypanosomiasis in the study area

To determine risk factors associated with trypanosomosis infection

To determine the species of trypanosoma associated with the diseases

\section{MATERials AND MethodS}

\subsection{Study Area}

The study was conducted in Tarcha Zuria Distric of Southern Region of Ethiopia. It is located at about $535 \mathrm{~km}$ of south of Addis Ababa and the study areas elevation ranges from 1000 to 2300 meter above sea level. The rainfall distribution is bimodal with highest fall at wet season (April to September) and lowest fall at last half of dry season (February to March). The mean annual rainfall ranges from 650 to $1100 \mathrm{~mm}$; the mean daily temperature is 18 to $23{ }^{\circ} \mathrm{C}$, respectively (TZWOA, 2018). According to agro-ecological classification criteria, the district is partitioned into three agro- ecological zones; namely highland (Dega), mid land (Woinadega) and lowland (Kola) with their total land holds of 53, 30 and $17 \%$, respectively. The major crops growing in the area are maize, teff, enset, and sweet potato and to lesser extent other crops (Tarcha Zuria Agricultural Office, 2018).

\subsection{Study Animal}

The livestock populations that are found in Tarcha Zuria District include indigenous cattle managed under traditional extensive husbandry systems with communal herding includes cattle, sheep, goats, mule, donkeys and poultry. Among these animals, cattle are the dominant species raised in the area. The cattle population in the three study peasant associations is estimated to be about 12,541 (TZWOA, 2018)). According to the information obtained from the agricultural office of the District, animal health problems, such as infectious diseases, internal and external parasitic diseases and 
protozoa diseases are the main constraints of livestock production and agricultural development in the District.

\subsection{Study Design}

A cross-sectional study was conducted from February, 12, 2018 to February 19, 2018 to determine the current prevalence of bovine trypanosomosis and to estimate the potential risk factors associated with the epidemiology. The study animals were selected by using simple random sampling method by taking age, sex, and body condition into account. The animals examined were categorized in different age groups as less than 3 years, between 3 up to 6 years and greater than 7 years. The body condition was estimated as per the recommendations of Nicholson and Butterworth (1986) for evaluating the body condition of the zebu cattle. The body condition of animals was recorded by classifying animals in the three groups as poor, medium and good based on the appearance of the ribs and dorsal spines.

\subsection{Sampling Method and Sample Size Determination}

The type of sampling methods was simple random sampling to determine the prevalence of bovine trypanosomosis using $95 \%$ confidence level and with the desired absolute precision 0.05.The sample size was determined by using formula given by (Thrusfield, 2005].

$$
N=1.962 \frac{P \exp (1-P \exp )}{d 2}
$$

Where: $\mathrm{N}=$ require sample size

Pexp $=$ expected prevalence

$\mathrm{d}=$ desire absolute precision

$1.96^{2}=$ z-value for the $95 \%$ confidence level.

By using the expected prevalence of $8.3 \%$ which was previously reported by Eshetu et al., (2016) a total of 117 cattle were sampled from tree peasant association that is 39 animals were sampled from each peasant associations (Wara, Sore and Aba Dahi ) in the study area.

\subsection{Study Methods}

\subsubsection{Blood Sample Collection}

Blood samples were collected after properly restraining the animal and aseptically preparing the sampling site. It was collected from the ear vein by using sterile blood lancet and hematocrit capillary tubes. A pair of heparinized hematocrit capillary tubes were filled with blood from animals to $3 / 4$ of the height and sealed at one end with crystal sealing material. The capillary tubes were loaded on the micro hematocrit centrifuge symmetrically and centrifuged at $1200 \mathrm{rpm}$ for $5 \mathrm{~min}$ (Murray et al., 1977).

\subsubsection{PCV Determination}

PCV was determined using hematocrit reader, which is used for the determination of anemia and comparison of infected animals with non-infected animals (Woo, 1969). After the PCV was read, capillary tubes were broken $1 \mathrm{~mm}$ below the buffy coat to include the red blood cell layer and the content were expressed on microscopic slide and mixed and covered with a $22 \times 22 \mathrm{~mm}$ cover slip, ground buffy coat technique (Murray et al., 1977).

\subsubsection{Buffy Coat Technique}

The capillary tube was cut using a diamond tipped pen $1 \mathrm{~mm}$ below the buffy coat to include the upper most layers of the red blood cells and $3 \mathrm{~mm}$ above to include the plasma. The content of the capillary tube was expressed on to a glass slide, and covered with cover slip. The slide was examined under $\mathrm{x} 40$ objective and $\mathrm{x} 10$ eye piece for movement of parasite was used. Trypanosome species were identified according to their morphological descriptions as well as movement in wet film preparations by (Murray et al., 1977).

\subsubsection{Data Management and Analysis}

Data about study sites and individual study animals were entered into Microsoft Excel. Hematological and parasitological data were managed very carefully. Then, the data from the Microsoft excel sheet 
were processed and analyzed by using a statistical software program (STATA 13). Descriptive statistics such as frequency, table and percentage were used to present the result. Percentage was used to compare the prevalence of trypanosomosis in different risk factors and Chi square statistics was used to determine the relationship between risk factors and prevalence. Data collected on PCV values were analyzed by t-test to compare the mean PCV values of parasitaemic animals against that of non parasitaemic animals. The prevalence of cattle trypanosomosis was calculated as the number of parasitologically positive animals. In all cases the difference between parameters were tested for significance at probability level of 0.05 or less.

\section{RESULT}

\subsection{Prevalence and Risk Factors for Trypanosomes Infection}

Out of the total animals examined, 8/117 (6.84\%) were infected with trypanosomes. The trypanosome species responsible for the infection was T. congolense. The Prevalence of trypanosomosis varies in both sexes; the infection in female is lower 4/73 (5.48 \%) than male 4/44 (9.10\%). But, the association was not statistically significant $(\mathrm{P}>0.05)$. Similarly, the prevalence of Trypanosomes infection in study animals with different body condition categories showed a relatively higher prevalence in medium body condition (12.5\%) followed by poor (7.14\%) and good body condition (4.44\%) animals. This variation was not statistically significant ( $p>0.05)$. In the present study, 1/34 (2.94\%) of animals under 3 years (young) old were found to be infected by Trypanosome congolense; 6/54 (11.11\%) for animals 3-6 years (adult) and 1/29(3.44 \%) for animals older than 7 years (old). The difference in the prevalence was not statistically significant $(\mathrm{p}>0.05)$. The prevalence of trypanosomosis among different peasant associations revealed a $3 / 39(7.69 \%)$ in Wara, $3 / 39(7.69 \%)$ in Sore and 2/39 $(5.13 \%)$ at Aba Dahi. However, this variation in prevalence of trypanosome infection among the peasant associations was not statistically significant ( $\mathrm{p}>0.05$ ) (Table1).

Table1. Prevalence of bovine trypanosomosis in Tarcha zuria district

\begin{tabular}{|c|c|c|c|c|}
\hline Risk factors & No. Examined & No. Positive (\%) & $95 \% \mathrm{CI}$ & p-value \\
\hline \multicolumn{5}{|l|}{ Sex } \\
\hline Male & 44 & $4(9.10)$ & $2.53-21.67$ & \multirow[t]{2}{*}{0.472} \\
\hline Female & 73 & $4(5.48)$ & $1.51-13.44$ & \\
\hline \multicolumn{5}{|l|}{ Body condition } \\
\hline Poor & 56 & $4(7.14)$ & $1.98-17.29$ & 0.544 \\
\hline Medium & 16 & $2(12.50)$ & $1.55-38.35$ & \\
\hline Good & 45 & $2(4.44)$ & $0.54-15.15$ & \\
\hline \multicolumn{5}{|l|}{ Age } \\
\hline <3years (Young) & 34 & $1(2.94)$ & $0.07-15.33$ & 0.237 \\
\hline 3-6years (Adult) & 54 & $6(11.11)$ & $4.19-22.63$ & \\
\hline$>7$ years $(\mathrm{Old})$ & 29 & $1(3.44)$ & $0.09-17.76$ & \\
\hline \multicolumn{5}{|c|}{ Peasant Associations } \\
\hline Wara & 39 & $3(7.69)$ & $1.61-20.87$ & 0.874 \\
\hline Sore & 39 & $3(7.69)$ & $1.61-20.87$ & \\
\hline Aba Dahi & 39 & $2(5.13)$ & $0.63-17.32$ & \\
\hline Overall & 117 & $8(6.84)$ & 3.00-13.03 & \\
\hline
\end{tabular}

\subsection{Hematological Survey Results}

The mean Packed Cell Volume (PCV) values for all examined animals were 25.93. However, the mean PCV for non-parasitamic animals were 26.34 and the mean PCV value of the parasitamic animals was 20.38. The association was found significant between non parasitamic and parasitamic animals $(\mathrm{P}<0.05)$ (Table 2).

Table2. Comparison of mean PCV among Parasitamic and non-parasitamic animals

\begin{tabular}{|l|l|l|l|l|l|}
\hline Animals & No. examined & Mean \pm SE & Mean difference & $\begin{array}{l}\text { 95\% CI of the mean } \\
\text { difference }\end{array}$ & p-value \\
\hline Parasitamic & 8 & $20.38 \pm 0.91$ & 5.96 & $2.496-9.433$ & 0.001 \\
\hline Non- Parasitamic & 109 & $26.34 \pm 0.47$ & & & \\
\hline Overall & $\mathbf{1 1 7}$ & $\mathbf{2 5 . 9 3 \pm 0 . 4 6}$ & & & \\
\hline
\end{tabular}

SE-Standard error; CI-Confidence interval 


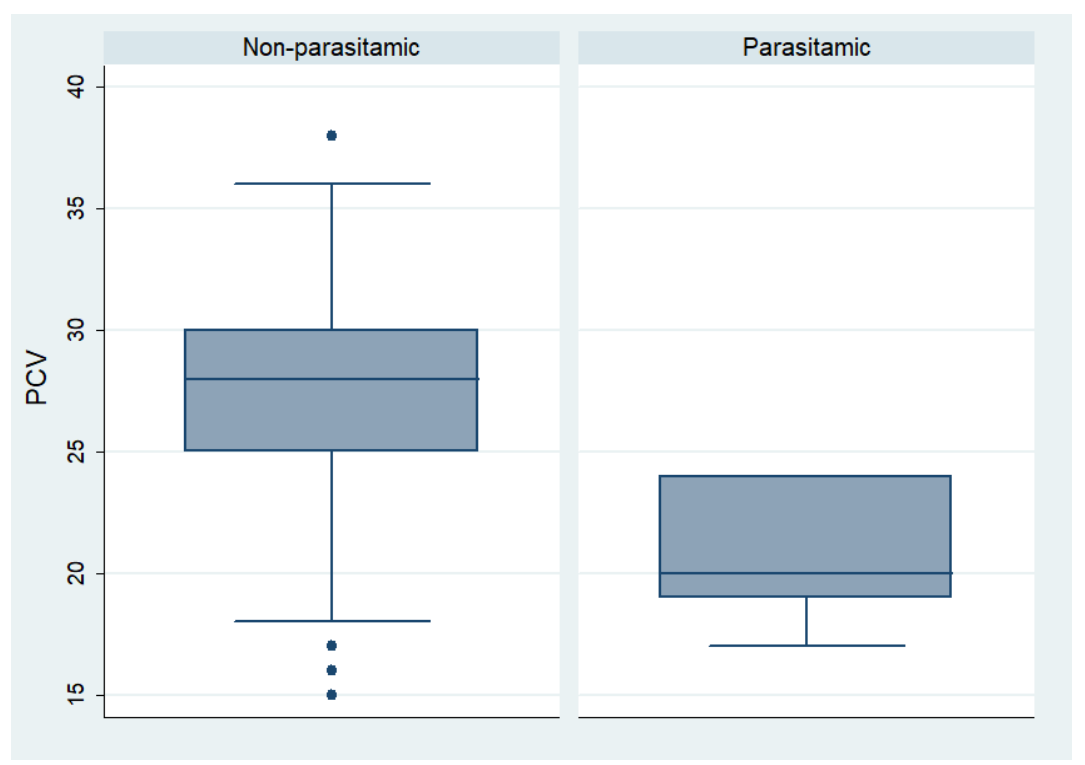

Figure1. Box plot showing PCV variation in Non-parasitamic and Parasitamic cattle

\section{DISCUSSION}

During the present study, an overall prevalence of 6.84\% (95\% CI=3.00-13.03) resulted. The result of the present study was similar to the reports of different reports by Habtewold (1993) at Humbo Larena of Wolaita zone 9.3\%, Keffale et al., (2017) at Darab District Sidamo Zone, Southern Ethiopia 14.8\%, Eshetu et al., (2016) at Maraka Woreda of Dawuro Zone, Southern Ethiopia 8.3\% were overall prevalence of bovine trypanosomosis.

In the present study, higher prevalence was observed in male animals $(9.10 \%)$ and similar result was reported by Magona et al., (2008) who reported that males had a non-significant higher prevalence of trypanosomosis than females. The possible reason for this finding in this study could be that both male and female animals are exposed to the same communal grazing land under extensive production system in the areas where tsetse challenge is equal for both sexes.

There was non- significant difference ( $>0.05)$ in infection rate among poor, medium and good body condition, that is, the result observed revealed the marked effect of trypanosomosis on the body condition of cattle. Animals with poor body condition were more associated with the disease as compared to animals with good body condition. Trypanosomosis cause weight loss (cachexia) and emaciation is the characteristic sign of trypanosomosis (Urquhart et al., 1996). This result is not different from the result revealed by Getnet (2008) in Soddo Zuria Woreda who observed that poor body condition $(7.14 \%)$ animals are more affected by trypanosomosis than good body condition (4.44\%) animals.

Based on age category, 2.94, 11.11 and $3.44 \%$ prevalence was observed in animals less than three years (young), between three and six years (adult) and above 7 years(old) of age respectively are not statistically significant ( $>>0.05)$ (Table1). This could be associated the fact that adult animals travel long distance for grazing and draught as well as harvesting crops in areas of high tsetse challenge than calves Ayele at el., (2012).

There was no significant difference in trypanosomes prevalence between the study peasant association (p>0.05). This could be due to the geographical location of the three peasant association which are located in the same climatic zones and distribution of tsetse fly challenge in these areas where there is good forest coverage which is the sutable habitat for tsetse flies. Similar results were obtained by Getnet (2008) at Soddo Zuria Woreda.

The current study in terms of trypanosome species is in agreement with that of Muturi et al. (2000) and Bekele et al. (2010) who reported a high proportion of T. congolense in the Southern Rift Valley. The dominance of $\mathrm{T}$. congolense infection in cattle may be due to its transmission only by tsetse flies and the high number of seroderms of T. congolense as compared to T. vivax and the development of better immune response to T. vivax by the infected animal (Leak, 1999). 
Regarding the PCV determination, the mean PCV values for parasitamic animals were 20.38 and non parasitemic animals (26.34\%) with the mean difference to be 5.96. This variation in PCV values was statistically significant $(\mathrm{p}<0.05)$. Likewise, Van den Boossche and Rowlands (2001) stated that the average PCV of parasitologically negative animals was significantly higher than that of parasitologically positive animals. Therefore, trypanosomosis may be involved in adversely lowering the PCV value of infected animals.

\section{CONCLUSION AND RECOMMENDATIONS}

Bovine trypanosomosis is one of the major impediments to livestock development and agricultural production in study area contributing negatively to the overall development in general and to food security in particular. The results of the present study revealed that trypanosomosis is still prevalent at the study area. The prevalent species identified from infected animals in the study area was $\mathrm{T}$. congolense. Factors such as sex, body condition, age and peasant associations were not associated with the trypanosome infection in cattle at the study area. However the mean PCV value of infected animals was significantly higher than the mean PCV value of the non-infected animals. This signifies that trypanosomes are causing anaemia in cattle of the study area.

Therefore, based on the above conclusion the following recommendations are forwarded: suitable community-based tsetse and trypanosomosis control program should be designed and implemented; attempt should be made to expand government and private veterinary services to serve the community properly, proper and strict trypanocidal drug utilization and awareness creation to the farmers about the role of tsetse in transmission of the disease should be made and further studies on the epidemiological aspects and development of drug resistance in pathogenic trypanosomes are required.

\section{REFERENCES}

[1] Abebe G, Jobre Y (1996): Trypanosomosis A threat to cattle production in Ethiopia. Revue de Med Vet., 147: 897-902.

[2] Abebe G. (2005): Current Situation of Trypanosomosis. In: review article on: Trypanosomosis in Ethiopia. Ethiop J Biol Sci., 4: 75-121.

[3] Alsan M (2012): The effect of the tsetse fly on African development, National Bureau of Economic Research, 105 Massachusetts, Avenue, Suite 418, Cambridge, MA 02138, USA.

[4] Abebe G (2005). Trypanosomosis in Ethiopia. Ethiop. J. Biomed. Sci. 4(1):75-80.

[5] Ayele T, Ehrem D, Elias K, Tamiru B, Gizaw D, Mebrahtu G, Mebrat E (2012): Prevalence of Bovine Trypanosomiasis and Its Vector Density in Daramallo District, South Western Ethiopia. J. Adv. 2(6): 266-27

[6] Bekele J, Asmare K, Abebe G, Ayelet G, Esayas G (2010). Evaluation of Deltamethrin applications in the control of tsetse and trypanosomosis in the Southern Rift Ralley areas of Ethiopia. Between the Parasitological prevalence of trypanosomal infection in cattle and herd average packed cell volume. Acta Trop. 78:163-170.

[7] Getnet B (2008). Prevalence of bovine trypanosomosis in Soddo Zuria Wereda, SNNPRS. DVM thesis. Haramaya University, Ethiopia.

[8] Habtewold T (1993): Bovine trypanosomosis in Wolaita: Prevalence and Assessment of drug efficacy. DVM Thesis. Addis Abeba University, Debre Zeit, Ethiopia.

[9] ILEMOBADE, A. A. 2009. Tsetse and trypanosomosis in Africa:The challenges, the opportunities. Onderstepoort Journal of Veterinary Research. 9: pp235-246.

[10] KUZOE, F. A. S \& Schofield, C. J (20040: Strategic Review Of Traps And Targets For Tsetse And African Trypanosomiasis Control: World Health Organization on behalf of the Special Programme for Research and Training in Tropical Diseases.

[11] Langridge WP. (1976): Tsetse and trypanosomosis survey of Ethiopia. Ministry of overseas development UK. Pp. 1-40.

[12] Leak A (1999): Tsetse biology and ecology: the role in the epidemiology and control of trypanosomosis. CAB International. Wallingford (UK). pp. 152-210.

[13] Leak SGA (1988): Determination of tsetse challenge and its relationship with trypanosomosis prevalence. In: Livestock production in tsetse infested areas of Africa. ATLN, Nairobi, Kenya. Pp. 43-52.

[14] LETA, S., HABTAMU, Y., AlEMAYEHU, G., AYEle, B., CHANIE, M., TESFAYE, S. \& MESELE, F. 2015. Spatial analysis of the distribution of tsetse flies in Ethiopia using high resolution environmental datasets and Maxent modeling technique. Unknown. 
[15] Magona W, Walubengo J, Origin T (2008): Acute haemorrhagic syndrome of bovine trypanosomosis in Uganda. Acta Trop., 107:186-191.

[16] Murray N, Murran K, McIntyre M (1977): An Improved Parasitological Diagnosis of African Trypanosomosis. Trans. R. Soc. Trop. Med. Hyg., 71:325-326.

[17] Muturi KS (1999): Epidemiology of Bovine Trypanosomosis in selected sites of the Southern Rift Valley of Ethiopia. MSc Thesis, Addis Ababa, Univeristy with Freie Universitae, Berlin. Nairobi, Kenya. pp. 27-36.

[18] Rogers DJ, Hay SI, Packer MJ (1996). Predicting the distribution of tsetse flies in West Africa using temporal Fourier processed meteorological satellite data. Anim. Trop. Med. Parasitol. 96(3):225241.

[19] Slingenbergh JHW (1992). Tsetse control and Agricultural development in Ethiopia. World Anim Rev. 1992; 70/71: 30-36.

[20] Thrusfield MV (2005): Veterinary epidemiology 2nd ed. Black Well Science, Oxford. pp. 183-198.

[21] TZWOA (Tarcha Zuria District Office of Agriculture) (2018): Official Document on Livestock resources and land condition of the District, Unpublished.

[22] Uilenberg G.A (1998): field guide for diagnosis, treatment and prevention of African animal trypanosomosis. Adopted from the original edition by boyt WP. FAO, Rome. Pp 43-135.

[23] Urquhart GM, Armour G, Duncan JL, Dunne AM, Jennings FW (1996): Veterinary Parasitology. 2nd ed. Blackwel science, London, pp. 212-219.

[24] Woo PJK (1969). The hematological centrifugation technique for the detection of trypanosomes. Can. Vet. J. 200(47):921-923.

Citation: Esayas Balcha Madalcho, "A Study on the Prevalence of Bovine Trypanosomiasis and its Associated Risk Factors in Tarcha Zuria District, Dawuro Zone Southern Ethiopia" International Journal of Research Studies In Biosciences (Ijrsb), Vol. 7, no. 8, pp. 4-10, 2019. http://Dx.Doi.org/10.20431/23490365.0708002

Copyright: (C) 2019 Authors. This is an open-access article distributed under the terms of the Creative Commons Attribution License, which permits unrestricted use, distribution, and reproduction in any medium, provided the original author and source are credited. 